\title{
Paradoxical skin reaction with infliximab treatment
}

\author{
Reação cutânea paradoxal com tratamento com infliximabe
}

Larissa Starling de A. Fernandes, Daniela Martinez, Omar Lupi, Ricardo Barbosa Lima, Carlos José Martins, Antonio D`Acri

\begin{abstract}
Considering the increased utilization of anti-TNF medications in the treatment of inflammatory and autoimmune diseases, dermatologists should be aware of the possible adverse skin reactions. We describe a case of inverted psoriasis due to the use of infliximab used in the treatment of inflammatory bowel disease.
\end{abstract}

Key-words: Psoriasis. Inflximab. anti-TNF. Paradoxical Reaction. Inflammatory Bowel Diseases.

\section{RESUMO:}

Com o aumento do uso de anti-TNF no tratamento de doenças inflamatórias e auto-imunes, os dermatologistas devem estar conscientes da possibilidade de reações cutâneas adversas. Apresentamos um caso de psoríase invertida devido ao uso de infliximab utilizado no tratamento da doença inflamatória intestinal.

Palavras-chave: Psoríase. Infliximabe. anti-TNF. Reação Paradoxal. Doenças Inflamatórias Intestinais.

\section{INTRODUCTION}

The anti-TNF- $\alpha$, including adalimumab and infliximab, are drugs that have dramatically improved the prognosis of inflammatory bowel disease (Ulcerative colitis and Crohn's Disease). However, some concerns have recently emerged on antiTNF alpha induced inflammatory skin lesions, such as psoriasiform and eczematiform, lichenoid eruptions and lupus-erythematosus-skin-like. Other rare complications included neutrophilic dermatoses such as amicrobial pustulosis, which resembles the inverted psoriasis. All of these skin disorders represent a paradoxical reaction, especially the psoriasiform pattern, since anti-TNF- $\alpha$ therapies are commonly used for psoriasis treatment. Paradoxical psoriasis is a relevant side effect of anti-TNF- $\alpha$ therapy with an incidence rate of 5 per 100 personyears. ${ }^{1,2,3}$ We report the case of a patient with Crohn's Disease (CD) treated with infliximab who presented extensive psoriasiform skin lesions, inverse psoriasis-like.
Gaffree e Guinle University Hospital, Federal University of State of Rio de Janeiro (UNIRIO).

Conflict of Interest: The authors have no conflict of interest of regarding this paper.
CoRRESPONDÊNCIA: Larissa Starling de A. Fernandes starling_larissa@hotmail.com

Recebido em 18/10/2017 Aprovado em 10/04/2018 


\section{CASE REPORT}

A 56-year-old woman was referred for evaluation of desquamation involving her face, neck and scalp during the previous week. Her past medical history revealed that she had been diagnosed with CD ten years previously, with gastric, duodenal, distal ileum, cecum, colon and, at the present time, intense perianal involvement. She did not have any personal or familial history of psoriasis. She had been treated with mesalazine, azathioprine and adalimumabe, that was replaced to infliximab ( $5 \mathrm{mg} / \mathrm{kg}$ intravenously) with control of CD. Two years after infliximab introduction, after the 9th infusion, the eruption got worse with severe pruritus and extensive erythematous, scaly and exudative patches on the face, scalp and neck. There was progression to the flexural areas on the trunk and limbs. The nail plates were normal (Figure 1). Skin lesions became clearly psoriasiform coincidentally with an increase in the frequency of infliximab infusions (every 6 weeks). The inicial clinical diagnostic hypothesis were contact dermatitis, atopic dermatitis, seborrheic dermatitis and inverse psoriasis. Histopathological examination of a skin biopsy taken from her neck, close to the hairline, showed psoriasiform hyperplasia with marked parakeratosis, spongiosis exocytosis, superficial inflammatory infiltrate consisting of lymphocytes, eosinophils and necrotic keratinocytes (Figure 2). Results of laboratory tests were within normal limits. The clinical and histopathological findings, and the history of infliximab therapy led to the diagnosis of a paradoxical skin reaction inverse psoriasis-like. The treatment was started with topical betamethasone dipropionate, oral prednisone $20 \mathrm{mg} /$ day and oral acitretin $20 \mathrm{mg} /$ day. After discussing the case with the gastroenterologist, infliximab therapy was discontinued and there was slowly resolution of cutaneous lesion in 4 months. During this period skin directed therapy was progressively reduced. The improvement of the eruption after stopping infliximab reinforce the role of the antiTNF as a trigger for this reaction (Figure 3 ). For the $C D$ the patient remain using mesalazine and azathioprine. Vedolimumab was added to the therapy regimen to replace infliximab.

\section{DISCUSSION}

The paradoxical induction of psoriasis-like eruption under anti-TNF- $\alpha$ treatments was first reported by Verea et al in 2004 . These side effects, in particular psoriasis, have been defined "paradoxical", because anti-TNF- $\alpha$ are commonly used to treat wild psoriasis. The time between the introduction of the medication and the appearance of lesions can range from a few days to many months. ${ }^{1-7}$ The main risk factors are female sex, $C D$, personal or family history of inflammatory skin diseases, smoking, treatment with adalimumab, but there is not statistic difference with another anti-TNF- $\alpha{ }^{2}$

The triggering of inverse psoriasis as a paradoxical side effect to treatment with infliximab for Crohn's disease has been reported in the literature. ${ }^{3,4,8}$

Sometimes is difficult to diagnose this paradoxical reaction at the first visit. In this case our first hypothesis were contact and seborrheic dermatitis. We suspected that the eruption was a paradoxical reaction to infliximab because it was severely itchy, resembled inverse psoriasis and was refractory to treatment with topical corticosteroids and low dose oral prednisone. The patient was treated with corticosteroids due to our first hypothesis: contact and seborrheic dermatitis. So, a biopsy was performed revealing a spongiotic and psoriasiform dermatitis with some elements that suggest a drug reaction such as the presence of necrotic keratinocytes in the epidermis and eosinophils and melanophages in the papilar dermis indicating basal layer damage, which is more common in drug reactions and may not be present in paradoxical reactions. It's difficult to make the diagnosis with only histopathological findings.

Our patient denied any treatment of drugs associated with the development of psoriasis, such as beta-blockers, lithium, antimalarials, angiotensinconverting enzyme inhibitors, tetracyclines or nonsteroidal anti-inflammatory agents. Also, she denied symptoms of bacterial or viral infection preceding the beginning of the eruption and the results of the laboratory tests were within normal limits.

Another element that strongly suggest the role of infliximab as a trigger was the improve- 

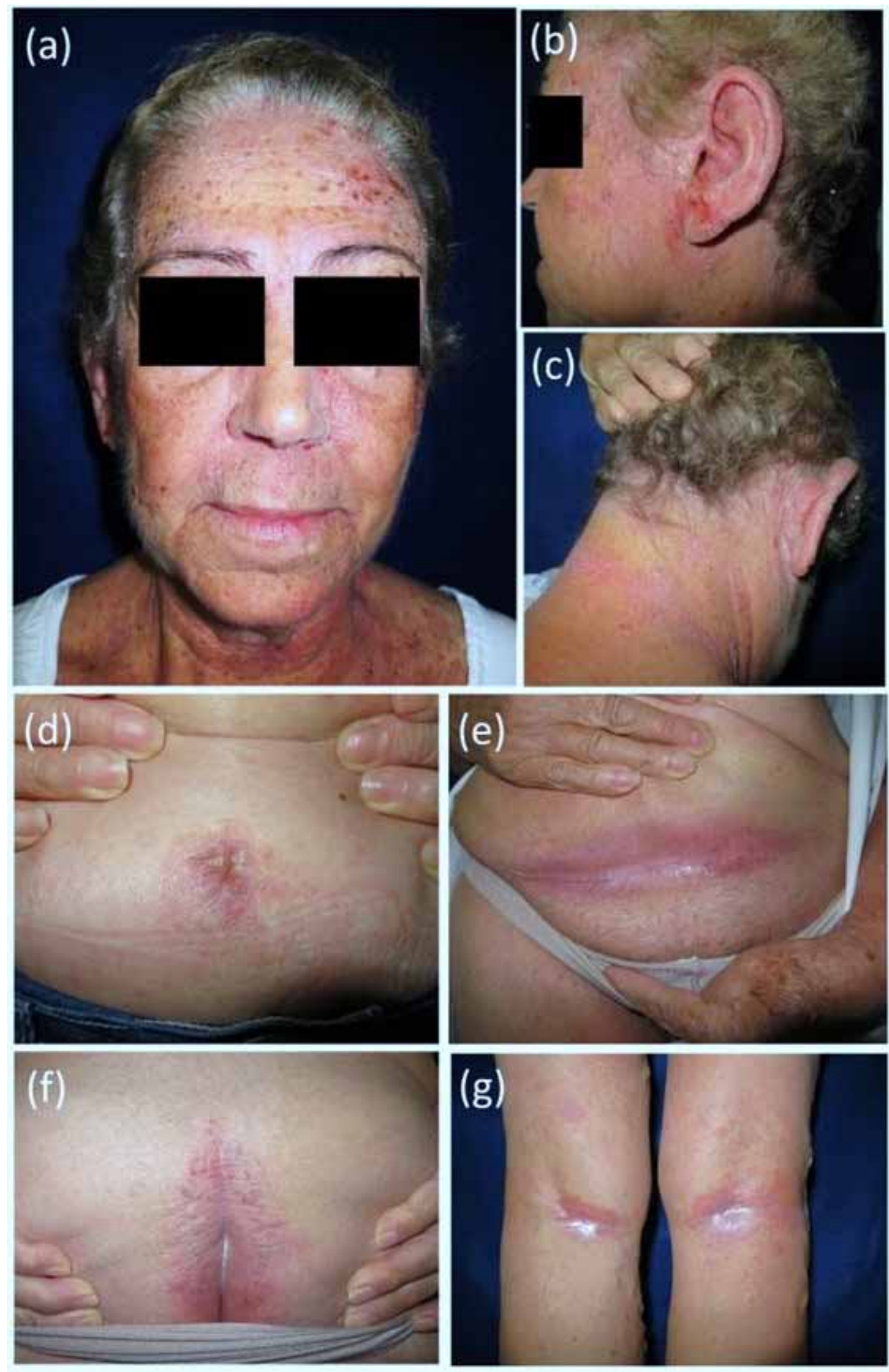

Figure 1: Extensive erythematous, scaly and exudative patches on the face, scalp and neck and flexural areas. 

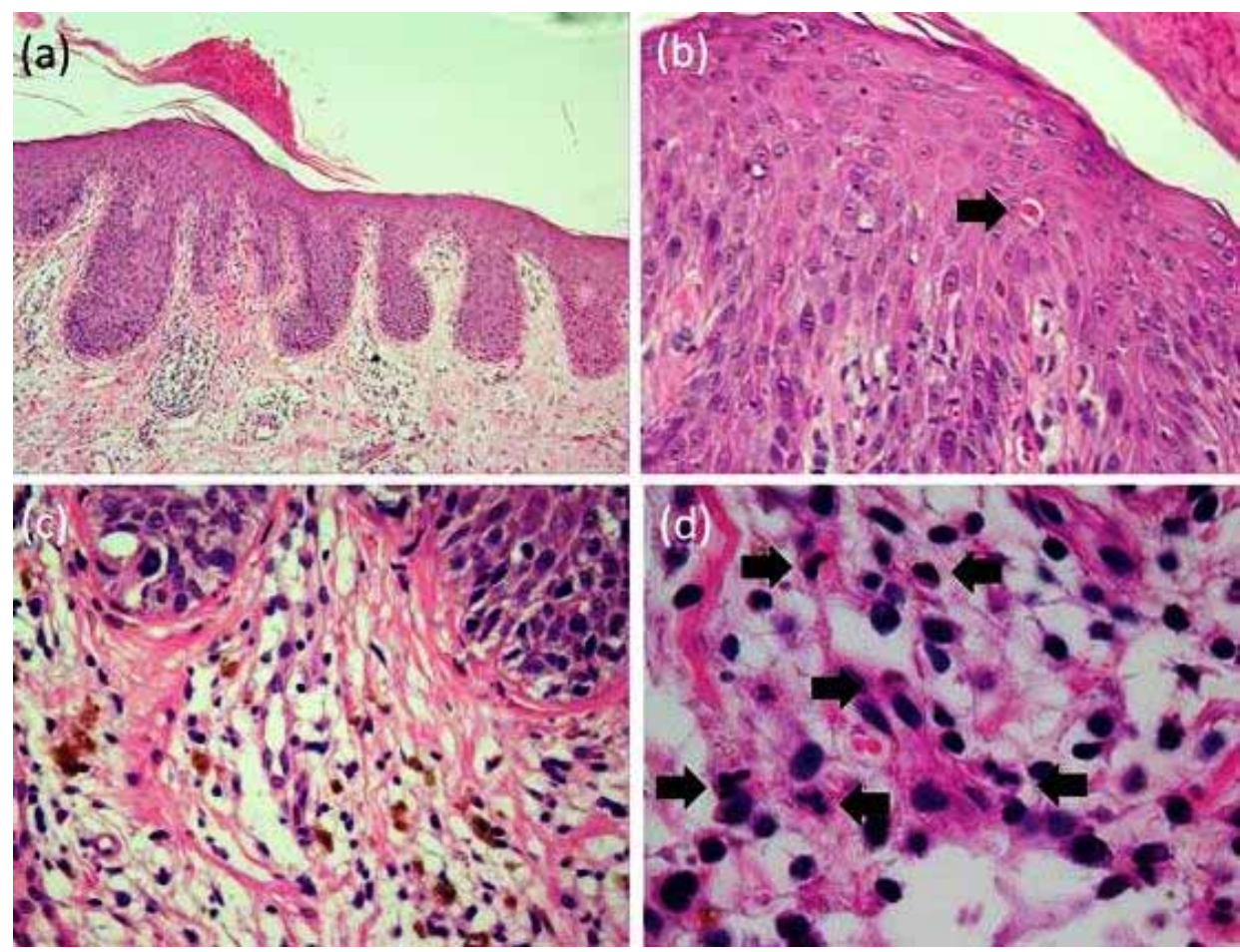

Figure 2: Histopathological examination of a skin biopsy taken from her neck, close to the hairline, showed psoriasiform hyperplasia with marked parakeratosis, spongiosis exocytosis, superficial inflammatory infiltrate consisting of lymphocytes, eosinophils and necrotic keratinocytes
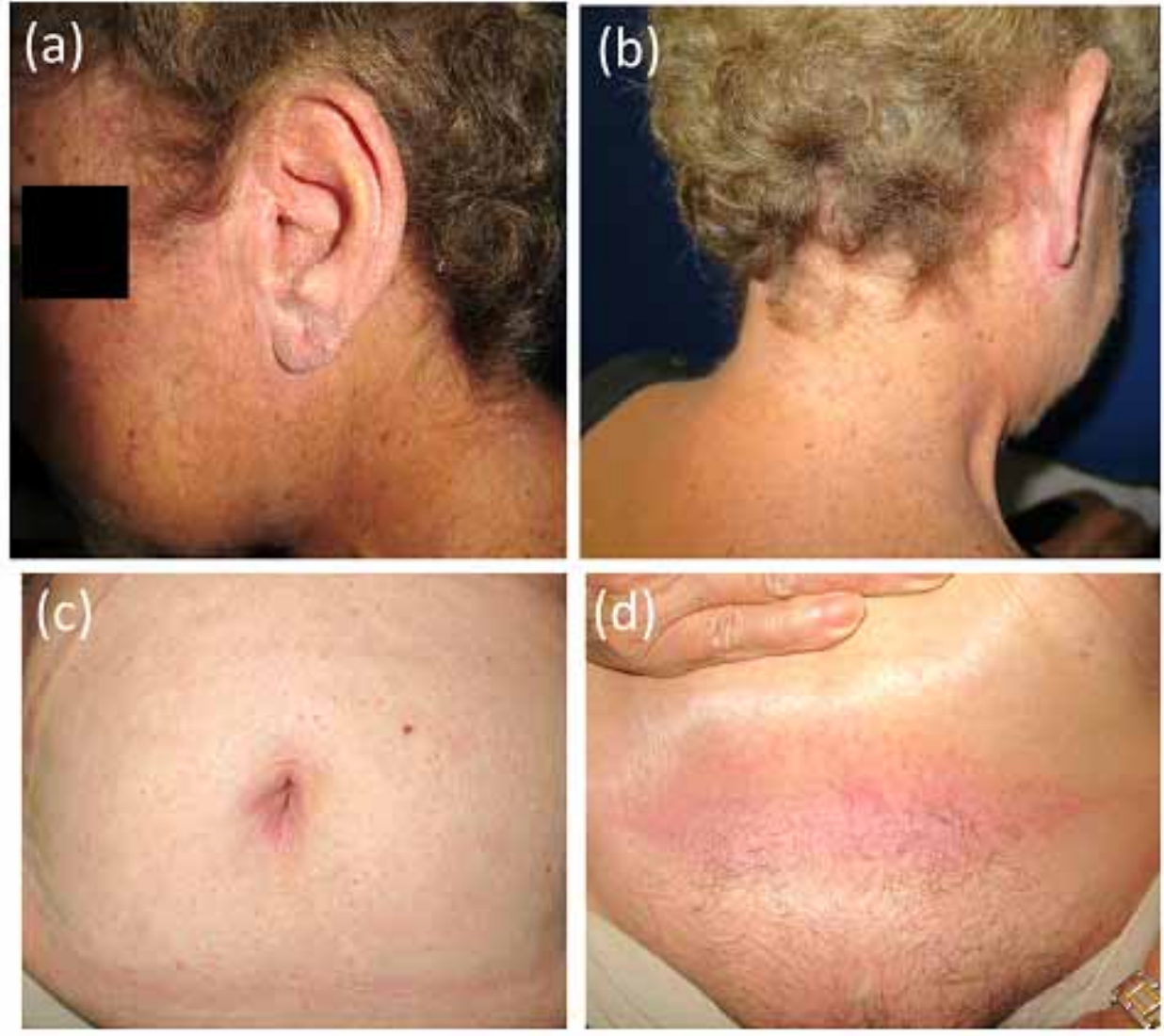

Figure 3: The improvement of the eruption after stopping infliximab. 
ment of the eruption after it was stopped. We and Gastroenterologist Service suspended infliximab because patient was scheduling to receive a new therapy with vedolimumab, which is indicated for inflamatory bowel disease refractory to anti-TNF- $\alpha$. The pathogenesis has not been fully understood, but it seems that imbalance between different cytokines and activated inflammatory pathways can cause the onset and/or the aggravation of these skin lesions. Regarding anti-TNF- $\alpha$ induced psoriasis, it has been speculated that the inhibition of TNF- $\alpha$ by antibody drugs may stimulate uncontrolled production IFN- $\alpha$ by plasmacytoid dendritic cells, inducing the recruitment of $T$ cells and the secretion of pro-inflammatory cytokines IL12/23, thereby inducing paradoxical reactions or psoriasis. The combination therapy with anti-TNF- $\alpha$ plus immunosupressants is associated with a reduced risk of paradoxical psoriasis. ${ }^{1-7}$

In case of development of suggestive psoriasiform lesions, a dermatology evaluation with eventual biopsy is mandatory. When patients need a maintenance therapy for the inflammatory bowel disease (IBD), a switch to a different anti-TNF- $\alpha$ or to an immunosuppressant, such as cyclosporine, methotrexate, could be attempted, according to the intestinal activity and the previous drug history. The suspension of the anti-TNF drug associated with the start of systemic medication for psoriasis resulted in higher cure rates: approximately $64 \%$ versus $44 \%$ when systemic medications started without suspension of the immunobiological agent. A systematic review of 222 patients with IBD treated with anti-TNF- $\alpha$, with paradoxical reaction showed that most were adult women, with CD treated with infliximab. ${ }^{1,3,9}$ Paradoxical psoriasiform reactions can be divided clinically into de novo psoriasis and exacerbation of preexisting psoriasis. The first, which is more common and more extensively described in the literature, occurs in patients without a history of psoriasis who are receiving TNF- $\alpha$ therapy for another inflammatory disorder. The second can occur with or without changes in the morphology of the lesions. ${ }^{10}$

This review indicated that the psoriasiform reactions into de novo psoriasis were more prevalent than the typical history previously psoriasis.

\section{Acknowledgements}

With this case report, we aim to illustrate a peculiar type of psoriasiform reaction to infliximab inverse psoriasis-like. It was difficult to diagnose at first time and with the increasing use of anti-TNF- ? in the treatment of inflammatory and autoimmune diseases, these reactions will be more common and dermatologists should be aware of the clinical and histopathological aspects of them.

\section{REFERENCES}

1- Denadai R, Teixeira FV, Steinwurz F, Romiti R, Saad-Hossne R. Induction or exacerbation of psoriatic lesions during anti-TNF-? therapy for inflammatory bowel disease: asystematic literature review based on 222 cases. J Crohn's Colitis. 2013; 7:517-24.

2- Pugliese D, Guidi L, Ferraro PM, Marzo M, Felice C, Celleno $L$, et al. Paradoxical psoriasis in a large cohort of patients with inflammatory bowel disease receiving treatment with anti-TNF alpha: 5-year follow-up study. Aliment Pharmacol Ther. 2015; 42:880-8.

3- Seneschal J, Milpied B., Vergier B., Lepreux S., Schaeverbeke T., Taieb A. Cytokine imbalance with increased production of interferon-a in psoriasiform eruptions associated with antitumour necrosis factor-a treatments. British J Dermatol. 2009; 161: 1081-88.

4- Peramiquel L, Puig L, Dalmau J, Ricart E, Roe E, Alomar A. Onset of flexural psoriasis during infliximab treatment for Crohn's disease. Clin Exp Dermatol. 2005; 30:713-4.

5- Marzano AV, Tavecchio S, Berti E, Gelmetti C, Cugno M. Paradoxical Autoinflammatory Skin Reaction to Tumor Necrosis Factor Alpha Blockers Manifesting as Amicrobial Pustulosis of the Folds in Patients with Inflammatory Bowel Diseases. Medicine (Baltimore). 2015; 94: e1818.

6- Coutzac C, Chapuis J, Poullenot F, Chabrun E, Capdepont M, Blanco P, Laharie D. Association Between Infliximab Trough Levels and the Occurrence of Paradoxical Manifestations in Patients with Inflammatory Bowel Disease: a Case-Control Study. J Crohns Colitis. 2015; 9:982-7.

7- Verea MM, Pozo DJ, Yebra-Pimentel MT, et al. Psoriasiform eruption induced by infliximab. The Annals of Pharmacotherapy. 2004; 8: 54-7.

8- Omland SH, Gniadecki R. Psoriasis inversa: A separate identity or a variant of psoriasis vulgaris? Clin Dermatol. 2015; 33:456-61.

9- Vasconcelos J B, Pereira DN, Vargas TJS, Levy RA, Pinheiro GRC, Cursi IB. Paradoxical psoriasis after the use of antiTNF in a patient with rheumatoid arthritis. An Bras Dermatol. 2016;91(5 Supl ): S137-9.

10- R. Navarro, E. Daudén. Reacciones psoriasiformes paradójicas durante el tratamiento con terapia anti-factor de necrosis tumoral. Manejo clínico. Actas Dermosifiliogr 2014; 105: 752-61. 